\title{
Metal organic framework MIL-101(Cr) for dehydration reactions
}

\author{
M SURESH, B DAVID RAJU, K S RAMA RAO, K RAVEENDRANATH REDDY, \\ M LAKSHMI KANTAM and PAVULURI SRINIVASU* \\ Inorganic and Physical Chemistry Division, CSIR-Indian Institute of Chemical Technology, \\ Hyderabad 500 007, India \\ e-mail: pavuluri.srini@iict.res.in
}

MS received 11 December 2013; revised 6 January 2014; accepted 7 February 2014

\begin{abstract}
Porous chromium terephthalate MIL-101 (Cr-MIL-101) has been prepared by direct method under hydrothermal conditions and characterized using X-ray diffraction, $\mathrm{N}_{2}$ sorption, TGA and FT-IR. The nitrogen adsorption-desorption isotherm shows that the Cr-MIL-101 possesses BET specific surface area of $2563 \mathrm{~m}^{2} / \mathrm{g}$. Catalytic performance of Cr-MIL-101 in the dehydration of 1,4-butanediol and 1-phenylethanol is assessed under vapour phase conditions in the temperature range of 513-533 K and time on stream (TOS) at $513 \mathrm{~K}$. Cr-MIL-101 demonstrates superior catalytic activity with conversion of 95\% of 1-phenylethanol. Moreover, high surface area and nanocages with coordinated unsaturated sites of Cr-MIL-101 have allowed us to attain higher dehydrated products selectivity than $\mathrm{Cr}$-supported activated carbon $(\mathrm{Cr} / \mathrm{AC})$, amberlyst-15 and HZSM-5 catalysts.
\end{abstract}

Keywords. Cr-MIL-101; 1,4-butanediol; 1-phenylethanol; dehydration reaction

\section{Introduction}

Porous metal organic frameworks (MOFs) are of significant interest both in academics and industry due to their coordination structure, diverse topologies and potential applications in gas storage, separation, catalysis and drug delivery. ${ }^{1}$ MOFs possess unique two or three dimensional structures formed by the self-assembly of metal ions or metal clusters (the connectors) are bridged with polytopic organic ligands as linkers, which allows the design of specific nanometer-scale framework geometries with pore structures. In particular, the coordinated unsaturated sites in MOFs play an important role in catalysis as metals or cations are Lewis acidic centres and the organic linkers or anions are Lewis-basic centres. Although, MOFs are currently of great interest in many research areas, catalytic applications of these materials have not been explored much. Recently, the heterometallic $[\mathrm{Cu}(\mathrm{II}) / \mathrm{Fe}(\mathrm{II})]$-coordinated polymer has been reported for catalytic reactions; however, the catalyst dissolved partially in the employed reaction conditions. Among many other MOFs with one and two-dimensional structures, the porous chromium(III) terephthalate, Cr-MIL-101 has a rigid zeotype crystal structure with two types of quasi-spherical cages limited by 12 pentagonal faces for the smaller and 16 faces

\footnotetext{
*For correspondence
}

(12 pentagonal and 4 hexagonal) and pore diameter is close to 29 and $34 \AA$ A. In Cr-MIL-101, two coordinated unsaturated sites in trimeric $\mathrm{Cr}$ (III) octahedral cluster are formed after heating two water molecules at $423 \mathrm{~K}$ in air, which act as Lewis acidic site or catalytic active site in organic transformation reactions. ${ }^{2-4}$ In recent years, synthesis of fine, specialty chemicals and their derivatives have rapidly garnered tremendous interest as these products provide access to various synthetic intermediates. In particular, tetrahydrofuran (THF) has been used as a one of the important solvents in organic reactions, as precursor for polyurethane, elastic fibres; however, traditionally it is synthesized from maleic anhydride and its derivatives by hydrogenation over bimetallic Pd-Re-based catalysts. ${ }^{5-7}$ Moreover, $\mathrm{La}_{2} \mathrm{O}_{3}$, $\mathrm{Nd}_{2} \mathrm{O}_{3}, \mathrm{ZrO}_{2}, \mathrm{ZSM}-5$, Y-Zeolite, mordenite, ferrierite, amorphous silica and $\gamma$-alumina have been employed as catalysts for the preparation of THF from 1,4butanediol by cyclodehydration; but, the yields were less than $70 \% .^{8,9}$ On the other hand, dehydration of 1phenylethanol is one of the industrial important reactions to obtain styrene, which is one of the raw materials for polymers, and plastics. ${ }^{10,11}$ Dehydration reaction in gas phase has been carried out over solid acid catalysts such as silica gel, alumina, alkali alumina, aluminum silicates and $\mathrm{H}$-type synthetic zeolites and metal oxide catalysts such as titanium, thorium or aluminum oxide. ${ }^{12-15}$ Chromium-based catalysts were used for the transformation of alkyl aromatic to aromatic ketones 
and acids in homogenous medium; however, excess usage of chromium catalyst has adverse effect on environment due to toxic nature of chromium. ${ }^{16}$ Therefore, in recent years, considerable attention has been paid to development of chromium-based heterogeneous catalysts for wide variety of organic transformation such as oxidation of aromatic, dehydrogenation, epo-oxidation of olefins and allylic oxidation reactions. ${ }^{17-20}$ To the best of our knowledge, there are no reports available on dehydration of 1,4-butanediol and 1-phenylethanol reactions over Cr-MIL-101 catalyst. In the present study, cyclodehydration of 1,4-butanediol and dehydration of 1-phenylethanol over Cr-MIL-101 and $35 \mathrm{wt} \%$ $\mathrm{Cr} / \mathrm{AC}$ catalysts have been studied. In addition, effect of temperature and time on stream (TOS) on product selectivity and conversion are systematically investigated.

\section{Experimental}

\subsection{Preparation of chromium terephthalate (Cr-MIL-101)}

Cr-MIL-101 was prepared by the hydrothermal reaction of 1,4-benzene dicarboxylic acid $(1 \mathrm{mmol})$ with $\mathrm{Cr}\left(\mathrm{NO}_{3}\right)_{3} \cdot 9 \mathrm{H}_{2} \mathrm{O}(1 \mathrm{mmol})$, hydrofluoric acid $(1 \mathrm{mmol})$, and $\mathrm{H}_{2} \mathrm{O}(265 \mathrm{mmol})$ at $493 \mathrm{~K}$ for $8 \mathrm{~h}$. After cooling, unreacted carboxylic acid is removed by solvothermal method at $353 \mathrm{~K}$ for $24 \mathrm{~h}$ using $95 \%$ ethanol and $1 \mathrm{M}$ $\mathrm{NH}_{4} \mathrm{~F}$ solution at $343 \mathrm{~K}$ for $24 \mathrm{~h}$.

\subsection{Preparation of $35 w t \% \mathrm{Cr} / \mathrm{AC}$}

Activated carbon (M/S Norit, with surface area $\sim 1000 \mathrm{~m}^{2} \mathrm{~g}^{-1}$ ) has been purified by a sequential treatment with conc. $\mathrm{HNO}_{3}, \mathrm{NH}_{3}$ solution and distilled water followed by drying at $383 \mathrm{~K}$ for $10 \mathrm{~h} \cdot{ }^{21}$ Later, $35 \mathrm{wt} \%$ $\mathrm{Cr} / \mathrm{AC}$ was prepared by impregnation of aqueous solution of chromium nitrate nonahydrate on activated carbon. The resultant material was dried at $383 \mathrm{~K}$ followed by calcination at $823 \mathrm{~K}$ in presence of nitrogen for $5 \mathrm{~h}$.

\subsection{Characterizations}

Structural order of the prepared materials were determined using Rigaku Ultima-IV Powder X-ray diffractometer with $\mathrm{Ni}$-filtered $\mathrm{Cu} \mathrm{K} \alpha$ radiation $(\lambda=$ $1.5418 \AA$ A). Fourier transform infrared (FT-IR) analysis of the samples was performed with Perkin Elmer Spectrum GX FT-IR spectrometer using $\mathrm{KBr}$ discs, in the range of $4000-400 \mathrm{~cm}^{-1}$. Nitrogen adsorptiondesorption isotherms were determined by the Quantachrome Quadrasorb-SI at 77 K. Prior to measurement, the samples were degassed at $423 \mathrm{~K}$ to remove guest water molecules. Specific surface area was calculated using the Brunauer-Emmet-Teller (BET) method in the $P / P_{0}$ range of $0.05-0.3$. Average pore size determined from the isotherm and total pore volume is taken by a single point method at $P / P_{0}=0.99$. Thermogravimetric analysis was used to determine the thermal stability of materials on TGA Q500A analyser with heating rate of $10^{\circ} \mathrm{C} / \mathrm{min}$ in argon flow.

\subsection{Catalyst activity}

The catalytic activity study was carried over Cr-MIL101 and $35 \mathrm{wt} \% \mathrm{Cr} / \mathrm{AC}$ catalysts for dehydration of 1,4-butanediol and 1-phenylethanol in the temperature ranges of $513-533 \mathrm{~K}$ and $498-523 \mathrm{~K}$ in a fixed bed reactor. The products were collected in ice cold trap and analysed by HP 6890 series gas chromatography having flame ionization detector, using OVI-101 capillary column (0.32 i.d $30 \mathrm{~m}$ length and $0.25 \mu \mathrm{m}$ film thickness). The obtained products are further confirmed by Shimadzu GCMS-QP 5050A on ZB-Wax capillary column (30 m length, $0.53 \mathrm{~mm}$ id and $0.25 \mu \mathrm{m}$ film thickness).

\section{Results and discussion}

The powder X-ray diffraction patterns of chromium terephthalate (Cr-MIL-101) shown in figure 1, indicate well-resolved diffraction reflection of (022), (113), (115), (228) and (357) corresponding to cubic structure. ${ }^{22}$ Intensity of the used catalyst increases due to deposition of unreacted reactants on the catalyst surface from the reaction mixture, which confirms that

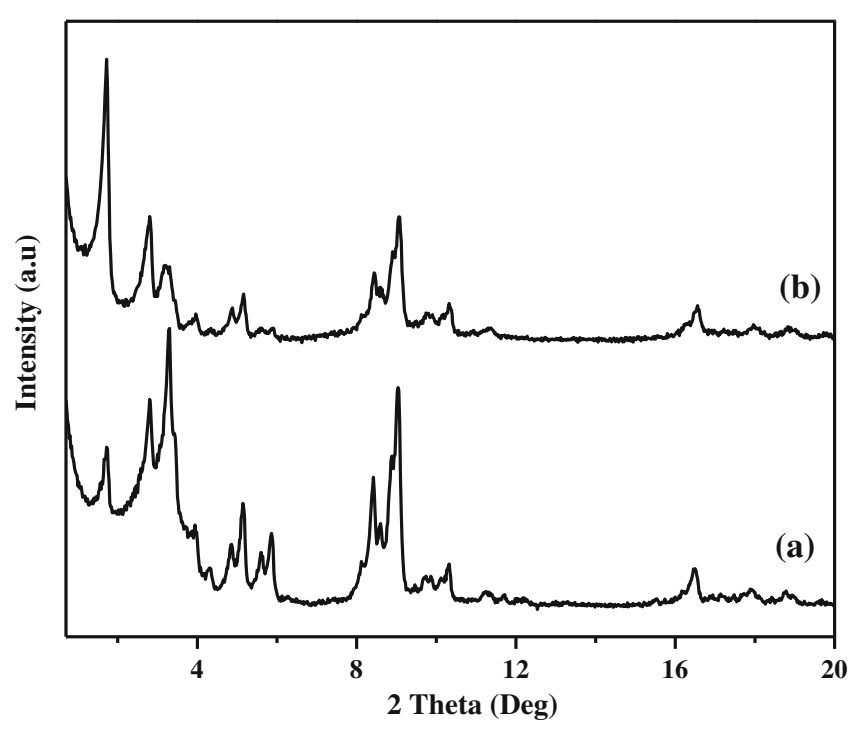

Figure 1. XRD patterns of Cr-MIL-101 (a) fresh and (b) used catalysts. 


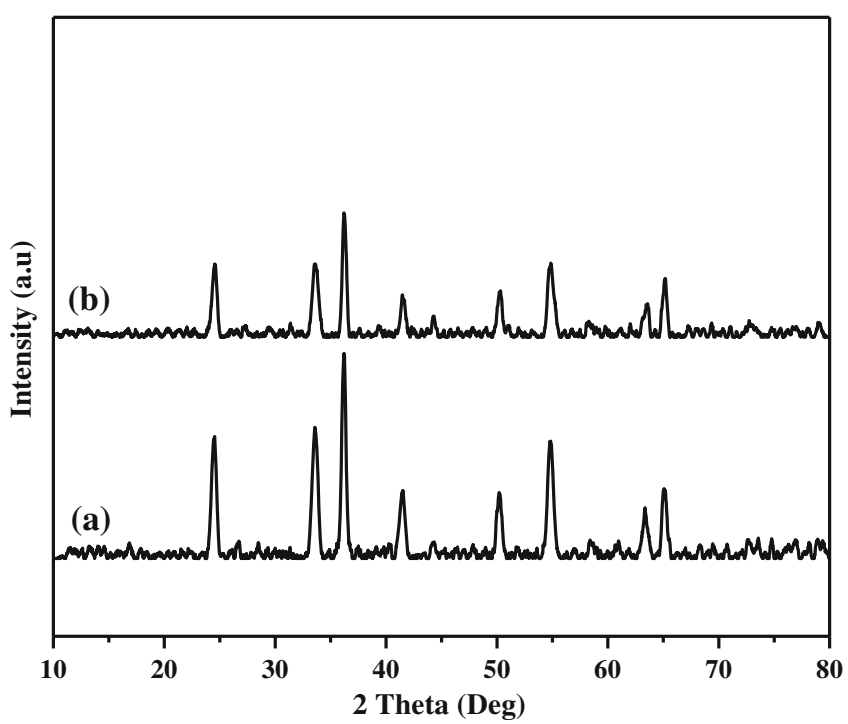

Figure 2. XRD pattern of $35 \mathrm{wt} \% \mathrm{Cr} / \mathrm{AC}$ (a) fresh and (b) used catalysts.

the structural order was intact after the reaction. ${ }^{23}$ The diffraction pattern in figure 2 shows reflections that match well with rhombohedral chromium oxide (CAS No: 85-0730). There is no change in the crystallinity of used catalyst of $35 \mathrm{wt} \% \mathrm{Cr} / \mathrm{AC}$ (figure 2b). Textural properties of Cr-MIL-101, activated carbon (AC), $35 \mathrm{wt} \% \mathrm{Cr} / \mathrm{AC}$ of fresh and used catalysts obtained from nitrogen adsorption-desorption isotherm are summarized in table 1 . The specific surface area and pore volume of as-synthesized Cr-MIL-101 which are $2563 \mathrm{~m}^{2} \mathrm{~g}^{-1}$ and $1.44 \mathrm{~cm}^{3} \mathrm{~g}^{-1}$, respectively; decrease to $2019 \mathrm{~m}^{2} \mathrm{gm}^{-1}$ and $1.19 \mathrm{~cm}^{3} \mathrm{gm}^{-1}$ due to formation of coke on the surface of catalyst (figure 3a). Similarly, in case of $35 \mathrm{wt} \% \mathrm{Cr} / \mathrm{AC}$, specific surface area and pore volume of as-synthesized are $375 \mathrm{~m}^{2} \mathrm{~g}^{-1}$ and $0.29 \mathrm{~cm}^{3} \mathrm{~g}^{-1}$, decrease to $288 \mathrm{~m}^{2} \mathrm{~g}^{-1}$ and $0.21 \mathrm{~cm}^{3} \mathrm{~g}^{-1}$, respectively, which are lower than the specific surface area $\left(905 \mathrm{~m}^{2} \mathrm{~g}^{-1}\right)$ and pore volume $\left(0.55 \mathrm{~cm}^{3} \mathrm{~g}^{-1}\right)$ of $\mathrm{AC}$ due to pore blocking by chromia (figure $3 \mathrm{~b}$ ). FTIR pattern of Cr-MIL-101 is shown in figure 4. The
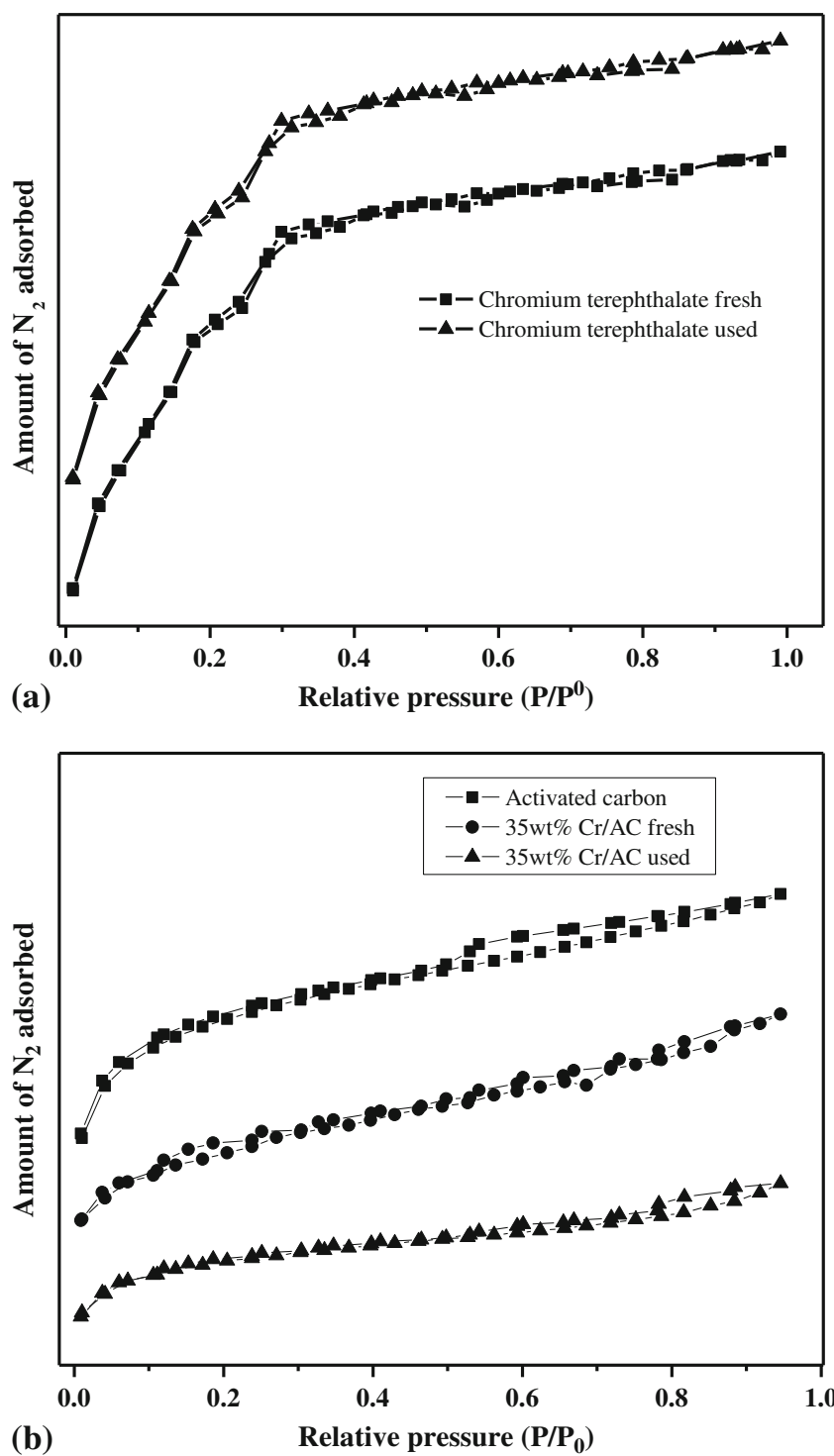

Figure 3. $\mathrm{N}_{2}$ adsorption studies of (a) Cr-MIL-101 and (b) $35 \mathrm{wt} \% \mathrm{Cr} / \mathrm{AC}$ catalysts.

band at $1403 \mathrm{~cm}^{-1}$ corresponds to symmetric vibrations (O-C-O) of dicarboxylate in the framework. On the other hand, stretching and bending vibration bands corresponding to benzene ring are observed at $1600-600 \mathrm{~cm}^{-1} \cdot{ }^{24}$ Thermogravimetric analyses of

Table 1. Textural properties of Cr-MIL-101, AC and 35 wt\% Cr/AC.

\begin{tabular}{lccc}
\hline Catalysts & Surface area $^{\mathrm{a}}\left(\mathrm{m}^{2} \mathrm{~g}^{-1}\right)$ & ${\text { Average pore } \operatorname{size}^{\mathrm{b}}(\mathrm{n} . \mathrm{m})}$ & Pore volume $^{\mathrm{c}}\left(\mathrm{cm}^{3} \mathrm{~g}^{-1}\right)$ \\
\hline Cr-MIL-101 (fresh) & 2563 & 2.25 & 1.44 \\
Cr-MIL-101 (used) & 2019 & 2.36 & 1.19 \\
Activate carbon (AC) & 905 & 2.43 & 0.55 \\
$35 \mathrm{wt} \%$ Cr/AC (fresh) & 375 & 3.09 & 0.29 \\
$35 \mathrm{wt} \%$ Cr/AC (used) & 288 & 2.92 & 0.21 \\
\hline
\end{tabular}

${ }^{\mathrm{a} B E T}$ method

${ }^{\mathrm{b}} \mathrm{BJH}$ method

${ }^{\mathrm{c}}$ At $P / P_{0}$ of 0.99 


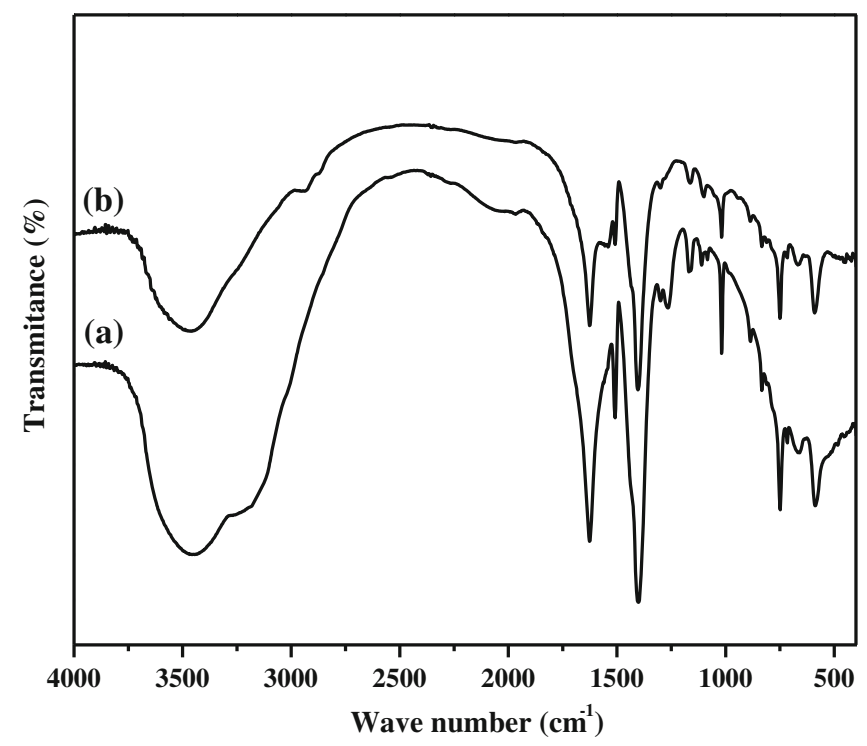

Figure 4. FT-IR analysis of Cr-MIL-101, (a) fresh and (b) used catalyst

Cr-MIL-101 and $35 \mathrm{wt} \% \mathrm{Cr} / \mathrm{AC}$ are depicted in figure 5 . Removal of guest water molecules at 323-373 K and elimination of $\mathrm{OH} / \mathrm{F}$ groups at $523-673 \mathrm{~K}$ for Cr-MIL101 are observed, which leads to decomposition of the framework. ${ }^{25,26}$ However, in the case of $35 \mathrm{wt} \% \mathrm{Cr} / \mathrm{AC}$, weight loss in the range of 373-473 K indicates decomposition of nitrate group leading to formation of $\mathrm{Cr}_{2} \mathrm{O}_{3}$ on AC.

The vapour phase cyclodehydration of 1, 4-butanediol has been studied over Cr-MIL-101 and $35 \mathrm{wt} \%$ $\mathrm{Cr} / \mathrm{AC}$ catalysts in the temperature range of 513-523 K (scheme 1). Cr-MIL-101 shows highest conversion of $99 \%$ of 1,4-butanediol at $513 \mathrm{~K}$ with $100 \%$ selectivity

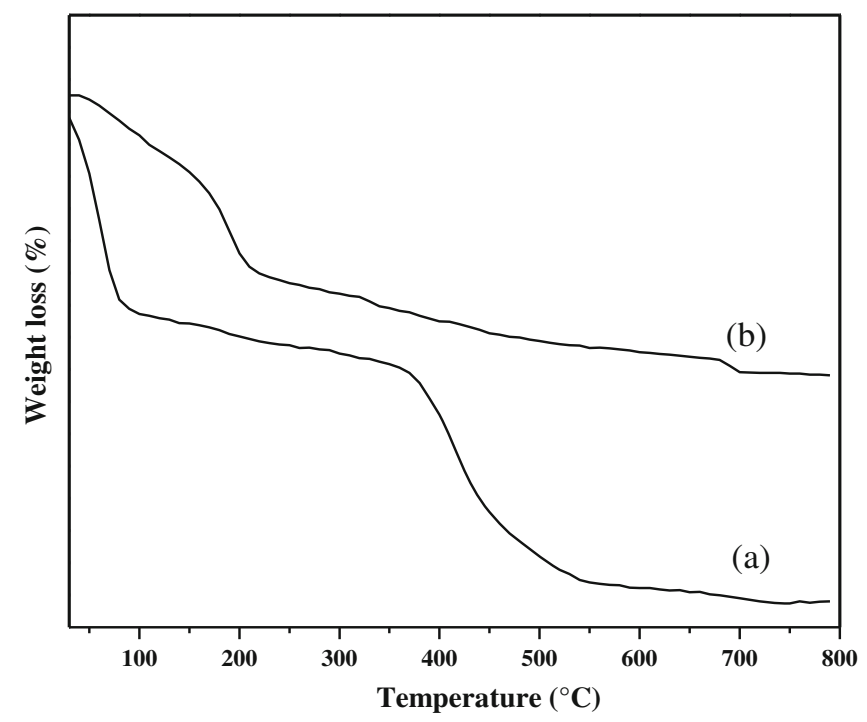

Figure 5. TGA analysis of (a) Cr-MIL-101 and (b) $35 \mathrm{wt} \%$ $\mathrm{Cr} / \mathrm{AC}$ catalysts.

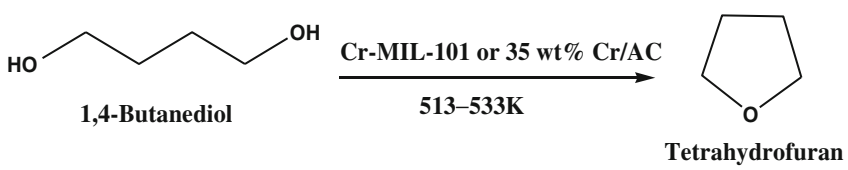

Scheme 1. Cyclodehydration of 1, 4-butanediol to tetrahydrofuran.

of tetrahydrofuran (THF). However, conversion of 1,4butanediol is only $28 \%$ when $35 \mathrm{wt} \% \mathrm{Cr} / \mathrm{AC}$ is used as a catalyst (figure 6). Catalytic activity of Cr-MIL101 and $35 \mathrm{wt} \% \mathrm{Cr} / \mathrm{AC}$ is compared with various rare earth metal oxides and the results are summarized in table 2. ${ }^{27-31}$ The lowest conversion of 1,4-butanediol $(40.3 \%)$ and selectivity of THF $(2.7 \%)$ was reported over $\mathrm{Yb}_{2} \mathrm{O}_{3}$ among all other rare earth metal oxides due to higher basic nature of the catalyst. Decrease in number of acidic site with loading of $1.5 \mathrm{~mol} \%$ of $\mathrm{Na}$ in $\mathrm{ZrO}_{2}$ resulted in increase in selectivity of 3-buten-1ol. Cyclodehydration of 1,4-butanediol at temperature of $698 \mathrm{~K}$ shows $73.4 \%$ of conversion and $7.4 \%$ selectivity of THF and formation of by products such as 3buten-1-ol and 1,3-butadiene over $\mathrm{CeO}_{2}$ due to redox properties of the catalyst. The above results clearly confirm that Cr-MIL-101 shows superior catalytic activity over $35 \mathrm{wt} \% \mathrm{Cr} / \mathrm{AC}$ and other rare earth metal oxide catalysts due to presence of coordinated unsaturated chromium sites in Cr-MIL-101 catalyst. Interestingly, TOS results in figure 7 indicates there is no loss in catalytic activity and selectivity in THF for $10 \mathrm{~h}$ over Cr-MIL-101 catalyst.

On the other hand, catalytic activity of Cr-MIL-101 and $35 \mathrm{wt} \% \mathrm{Cr} / \mathrm{AC}$ has also been tested for dehydration

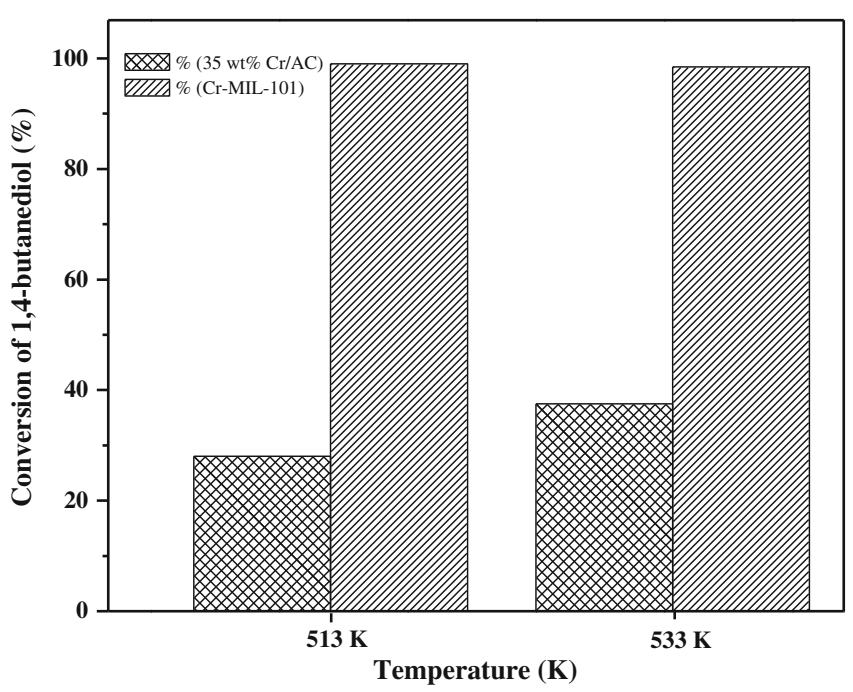

Figure 6. Effect of temperature on cyclodehydration of 1, 4-butanediol using Cr-MIL-101 and 35 wt\% Cr/AC. 
Table 2. Comparison of Cr-MIL-101 with literature reported catalysts in cyclodehydration of 1,4-butanediol over various oxide catalysts.

\begin{tabular}{lcccccc}
\hline \multirow{2}{*}{ Catalyst } & & & \multicolumn{3}{c}{ Selectivity } & \multirow{2}{*}{ References } \\
& Temperature (K) & Con. $(\%)$ & THF & 3-Buten-1-ol & Others & \\
$10 \mathrm{wt} \% \mathrm{La} / \mathrm{ZrO}_{2}$ & 598 & 94.4 & 65.9 & 34.1 & 0.0 & 27 \\
$\mathrm{Yb}_{2} \mathrm{O}_{3}$ & 648 & 40.3 & 2.7 & 81.7 & 15.6 & 28 \\
$\mathrm{ZrO}_{2}$ & 623 & 86.4 & 44.9 & 48.0 & 7.1 & 29 \\
$\mathrm{Na}^{2} \mathrm{ZrO}_{2}$ & 648 & 90.1 & 28.0 & 62.1 & 9.9 & 30 \\
$\mathrm{CeO}_{2}$ & 698 & 73.4 & 7.4 & 55.8 & 36.8 & 31 \\
$\mathrm{Cr}-\mathrm{MIL} 101$ & 513 & 99 & 100 & - & - & Present study \\
35 wt\% Cr/AC & 513 & 28 & 100 & - & - & Present study \\
\hline
\end{tabular}

of 1-phenylethanol in the temperature range of 498$523 \mathrm{~K}$ (scheme 2). Figure 8 shows the effect of temperature on 1-phenylethanol conversion over Cr-MIL101 and 35 wt\% Cr/AC. Although, maximum selectivity is obtained for both the catalysts, conversion of 1-phenylethanol over $35 \% \mathrm{Cr} / \mathrm{AC}$ is $95 \%$ at $523 \mathrm{~K}$, which is slightly higher than conversion obtained over Cr-MIL-101 catalyst. However, the TOS activity studies for $10 \mathrm{~h}$ indicate that decrease in 1-phenylethanol conversion from $93 \%$ to $63 \%$ is observed over $35 \% \mathrm{Cr} / \mathrm{AC}$, due to formation of coke (figure 9). Interestingly, activity and selectivity are maintained for $10 \mathrm{~h}$ without

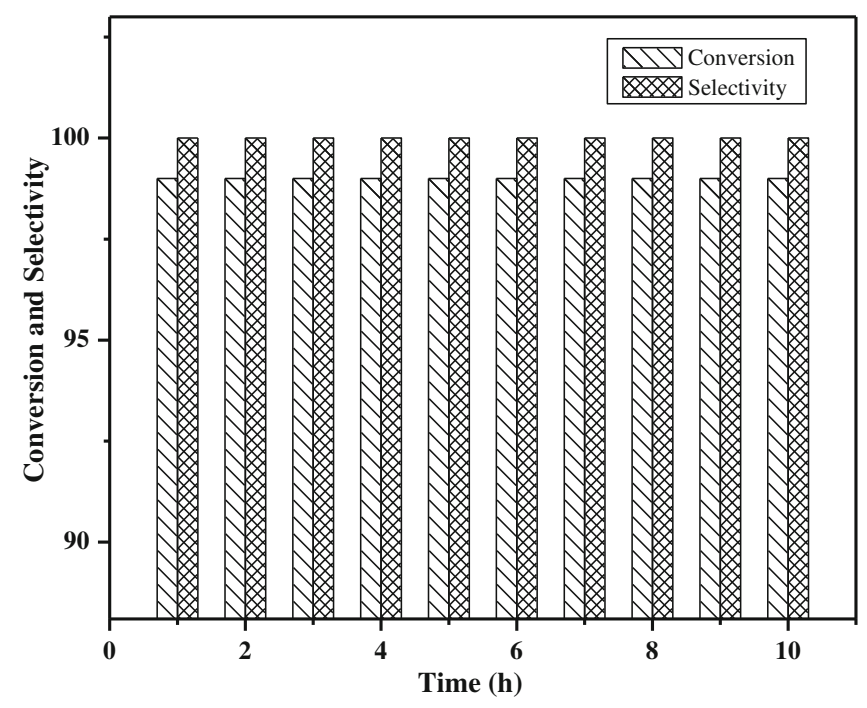

Figure 7. Time on stream on 1,4-butanediol using Cr-MIL101 catalyst.<smiles>CC(O)c1ccccc1</smiles>

1-Phenylethanol
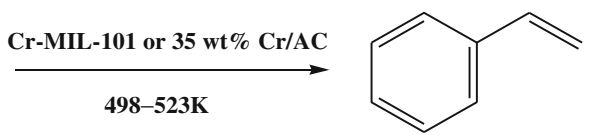

Styrene
Scheme 2. Dehydration of 1-phenylethanol to styrene.

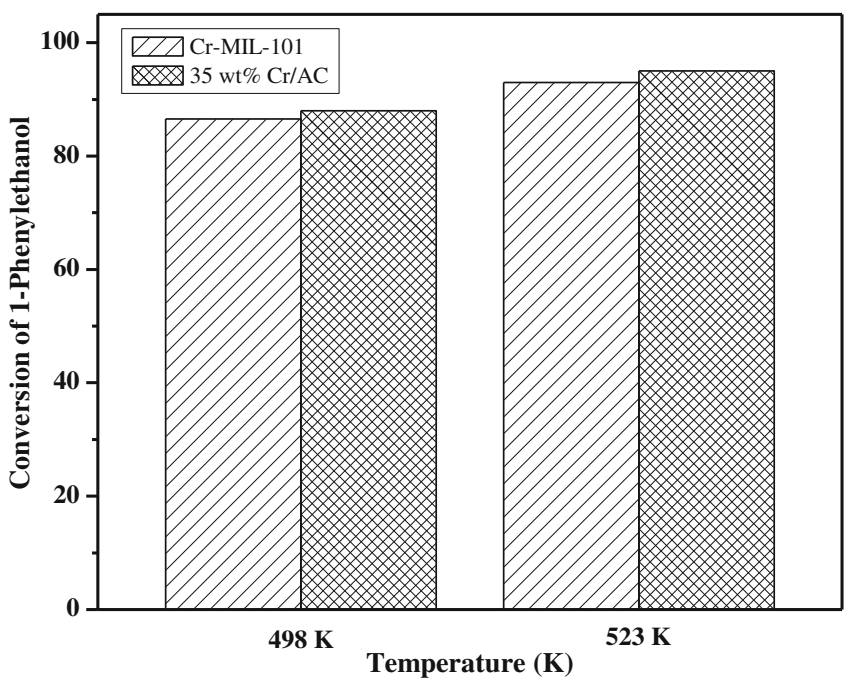

Figure 8. Effect of temperature on dehydration of 1-phenylethanol using Cr-MIL-101 and $35 \mathrm{wt} \% \mathrm{Cr} / \mathrm{AC}$.

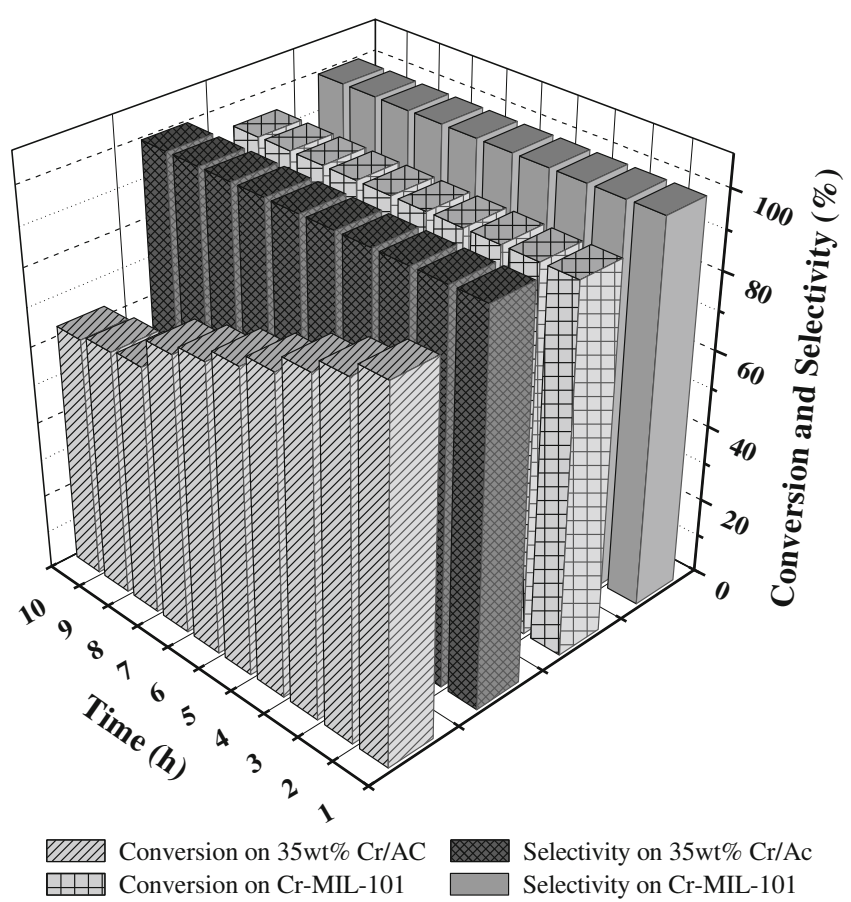

Figure 9. Time on stream on 1-phenylethanol using $\mathrm{Cr}$ MIL-101 and $35 \mathrm{wt} \% \mathrm{Cr} / \mathrm{AC}$. 
any loss when Cr-MIL-101 is used as catalyst. Results conclude that ordered porous cage structure with high surface area and more number of coordinated unsaturated chromium sites in Cr-MIL-101 favours higher activity.

\section{Conclusion}

In summary, a facile porous metal organic framework Cr-MIL-101 catalysed synthesis of tetrahydrofuran and styrene through dehydration reaction of 1,4-butanediol and 1-phenylethanol, respectively has been developed. Catalytic activity and selectivity are strongly influenced by ordered porous structure and coordinated unsaturated chromium sites of Cr-MIL-101 catalyst. Among the catalysts used in the present study, Cr-MIL-101 showed high conversion and selectivity under optimized reaction conditions, which is an interesting alternative to many current methodologies.

\section{Acknowledgement}

One of the authors MS thanks the Council of Scientific and Industrial Research (CSIR) New Delhi, India for the award of research fellowship.

\section{References}

1. Long J R and Yaghi O M 2009 Chem. Soc. Rev. 381213

2. Wang H, Du Z and Duan Q 2002 Chem. Ind. Eng. Prog. 21836

3. Ferry G, Draznieks C M, Serre C, Millange F, Dutour J, Surble S and Margiolaki I 2005 Science 3092040

4. Boehm H P, Knozinger H, Anderson J R and Boudart M 1984 Catal. Sci. Technol. 440

5. Hunter S E, Ehrenberger C E and Savage P E $2006 \mathrm{~J}$. Org. Chem. 716229

6. Mabry M, Prichard W and Ziemecki S 1985 E.I. DuPont de Nemours and Company USP $4 \mathbf{5 5 0} 185$

7. Mabry M, Prichard W and Ziemecki S 1986 E.I. DuPont de Nemours and Company USP 4609636

8. Herbert Muller 2002 Encyclopedia of Industrial Chemistry. (Wiley)
9. Li H, Yin H, Jiang T, Hu T, Wu J and Wada Y 2006 Catal. Commun. 7778

10. Nazmul A K, Jin S H and Sung H J 2011 Bull. Korean Chem. Soc. 321327

11. Chang J S, Hong D Y, Vislovskiy V P and Park S E 2007 Catal. Survey Asia 1159

12. Boelens M, Horton A D, Nisbet T M and Van Fort A B 2005 Process for Preparing Styrene. World Patent WO 054157 A1

13. Lamson J, Hall R H and Yats L D 1977 U.S. Patent 4049 736

14. Bos A and Koradia P B 2009 World Patent WO 074461 A1

15. Korchak E I 1967 U.S. Patent 3442963

16. Sakthivel A, Badamali S K and Selvam P 2002 Catal. Lett. 801

17. Michorczyk P, Ogonowski J, Kustrowski $\mathrm{P}$ and Chmielarz L 2008 Appl. Catal. A 34962

18. Nataliya V M, Konstantin A K, Sergey S A, Yurii A C, Maxim S M, Alexander G S, Vladimir P F and Kholdeeva A 2010 Inorg. Chem. 492920.

19. Maksimchu N V, Timofeeva M N, Melgunov M S, Shmakov A N, Chesalov Y A, Dybtsev D N, Fedin V P and Kholdeeva O A 2008 J. Catal. 257315

20. Li H, Yin H, Jiang T, Hu T, Wu J and Wada Y 2006 Catal. Commun. 7778

21. Siva Kumar V, Nagaraja B M, Shashikala V, Padmasri A H, Shakuntala Madhavendra S, David Raju B and Rama Rao K S 2004 J. Mol. Catal. A 223313

22. Yang J, Zhao Q, Li J and Dong J 2010 Micropor. Mesopor. Mater. 130174

23. Henschel A, Gedrich K, Kraehnert R and Kaskel S 2008 Chem. Commun. 4192

24. Zhang Z J, Huang S S, Xian S K, Xi H X and Li Z 2011 Energy Fuels 25835

25. Qing L, Liqi N, Shudong Z, Mengna T, Yao S and He Y 2013 Scientific Rep. 32916

26. Hwang Y K, Hong D Y, Chang J, Jhung S H, Seo Y K, Kim J, Vimont A, Daturi M, C Serre and Ferey G 2008 Angew. Chem. Int. Ed. 474144

27. Inoue $\mathrm{H}$, Sato $\mathrm{S}$, Takahashi R, Izawa $\mathrm{Y}$, Ohno $\mathrm{H}$ and Takahashi K 2009 Appl. Catal. A: General 35266

28. Igarashi A, Sato S, Takahashi R, Sodesawa $\mathrm{T}$ and Kobune M 2007 Catal. Commun. 8807

29. Yamamoto N, Sato S, Takahashi R and Inui K 2005 Catal. Commun. 6480

30. Yamamoto N, Sato S, Takahashi R and Inui K $2006 \mathrm{~J}$. Mol. Catal. A 24352

31. Sato S, Takahashi R, Sodesawa $\mathrm{T}$ and Yamamoto N 2004 Catal. Commun. 5397 